\title{
Microsoft's brush with regulators
}

\begin{abstract}
The largest software manufacturer's brush with US and European antitrust regulators might have been avoided if copies of software were sold not as if they were books but as intellectual property more broadly.
\end{abstract}

THE truism of the computer era is that even the most sophisticated hardware is no better than the software with which it is equipped. That is almost a sufficient explanation of the dazzling rise of the company called Microsoft in just under two decades to become the largest software manufacturer in the world and one of the largest public corporations. Its big break came in 1978, when it was chosen to supply the operating system called MS-DOS for the personal computer made by IBM, which then put the world at Microsoft's feet not only by selling huge numbers of its own machines, but by the liberality with which it allowed them to be cloned. Since then, as the world knows, IBM has fallen on hard times. What will happen to Microsoft now that it has tangled with the US Department of Justice and the European Commission and has been forced to sign an agreement to avoid alleged anticompetitive practices for the next six and a half years?

It is too soon to tell. The unfair practices of which Microsoft was accused (and which the company says are false) are too arcane for their commercial effects to be guessed at. If, as has been alleged, Microsoft required computer manufacturers to whom MS-DOS had been licensed to pay a royalty on every microprocessor they sold, whether or not it was loaded with Microsoft's operating system, the consequence a decade ago may have been to dissuade manufacturers from installing other operating systems in their machines. But now, when the tide has rolled in Microsoft's direction, the cost of rolling it back again would far outstrip whatever efforts could be mounted by a couple of bright people working from a garage (the legend of the computer industry in the United States). If there is ever a serious push in that direction, it is more likely to come from a Japanese manufacturer than from within the United States, the virtues of the rival UNIX notwithstanding.

That is the sense in which Microsoft may be a victim of its own success. It has been technically ingenious, and it has differed from most large companies in avoiding the almost inescapable complacency to which the successful are especially prone. No sooner is one piece of software successfully launched than it is improved and then resold (with discounts for those who own the earlier versions). At no stage has Microsoft been accused of lethargy, or its products decried for poor quality. That it has grown huge and rich is, on the face of things, an accurate market evaluation of its competence.

But there is a flaw in that argument affecting not just Microsoft but the whole of the software business. It has to do with copyright, and the terms on which computer programs should be sold to those who use them. The difficulty is easily illustrated (and commonly experienced). Suppose a person wishes to purchase a copy of his or her favourite wordprocessor called, say, Verbosity ${ }^{\mathrm{TM}}$ version 3.1 . The chances are that the software store will explain that version 3.1 has long since been outdated, that version 8.3 is now in stock, and that it has many more bells and whistles than the older version. The price, the store will say, is 395 (in local units of currency). The would-be purchaser's protest that version 3.1 will suffice for the purposes intended is unlikely to unlock a legal copy of the older version from the stock-room.

The flaw in that argument, which also underlies the alleged causes of Microsoft's brush with the US Department of Justice, is that software manufacturers regard their products as successive editions of a book while knowing (as do their customers) that there is no resale market for the older editions, which are in any case often physically tied to the machines in which they are embodied. But if Verbosity ${ }^{\mathrm{TM}} 3.1$ is no longer in print, natural justice (and patent, but not copyright, legislation) would require that others should be free to manufacture it. If some requirement of that kind were enforced, software manufacturers would quickly take to selling the bells and whistles separately from their core programmes. That is the direction in which the authorities should push the software manufacturers when they next have a chance to do so.

\section{Housekeeping at Oxford}

Britain's oldest university will have to struggle hard to keep its independence.

READY access to higher education is a civilizing force and an economic necessity in states pretending to be sophisticated, but there is inevitably a danger that wider access brings uniformity. That, it seems, is part of the reason why the University of Oxford has embarked on another bout of introspection about its internal administration, this time by means of an internal inquiry under the vice-chancellor, Dr Peter North. By all accounts, no questions are off limits. Even the question of whether the university might turn itself into a private institution may get a hearing, if perhaps a cursory one.

The University of Oxford is the oldest in Britain, but that 